\title{
UTILIZATION OF REAL-TIME PCR METHOD FOR IDENTIFICATION OF LISTERIA SPP. FROM HOMEMADE WHITE CHEESE ORIGINATING FROM SOUTHEAST OF TURKEY
}

\author{
Yigin, A. ${ }^{1 *}-$ KiliC Altun, S. $^{2}-$ DEMIRCI, M. ${ }^{3}-$ ESER, N. ${ }^{4}-$ YoldAS, A. ${ }^{5}$ \\ ${ }^{1}$ Harran University Veterinary Faculty, Department of Genetics, Şanliurfa, Turkey \\ (e-mail: akinyigin@yahoo.com) \\ ${ }^{2}$ Harran University Veterinary Faculty, Department of Food Hygiene and Technology, \\ Şanliurfa, Turkey \\ (e-mail: skilicaltun@harran.edu.tr) \\ ${ }^{3}$ Beykent University, School of Medicine, Department of Medical Microbiology, Istanbul, \\ Turkey \\ (e-mail:mdemirci1979@gmail.com) \\ ${ }^{4}$ Kahramanmaras Sutcu Imam University Medical Faculty, Department of Pharmacology, \\ Kahramanmaraş, Turkey \\ (e-mail: esernadire01@hotmail.com) \\ ${ }^{5}$ Kahramanmaras Sutcu Imam University Medical Faculty, Department of Anatomy, \\ Kahramanmaraş, Turkey \\ (e-mail: atillayoldas99@hotmail.com) \\ *Corresponding author \\ e-mail: vetserapaltun@hotmail.com; +90-41-4318-3000 \\ (Received $17^{\text {th }}$ Jan 2020; accepted $22^{\text {nd }}$ May 2020)
}

\begin{abstract}
This study, aimed to investigate the utilization of the real-time PCR method for the identification of Listeria spp., Listeria monocytogenes and Listeria innocua contamination in homemade white cheese samples produced around the southeast districts of Turkey. 103 white cheese samples were randomly selected from the local markets for investigation. ISO 11290-1/A1-2004 method was utilized for identification of Listeria spp. VITEK 2 GP cards were used to the identification the Listeria spp. using positive samples. The DNA was isolated from cheese samples directly and real-time PCR and Sanger sequencing were used to identify of Listeria monocytogenes and Listeria innocua by using specific primers designed for the hly and lin02483 genes. 6.7\% of samples were identified as Listeria spp. positive by VITEK 2, and Quantitative real-time PCR. 5.8\% of samples were contaminated with $L$. monocytogenes whereas $0.97 \%$ sample was $L$. innocua positive. The results of VITEK 2 and real-time PCR were found to be similar. These findings pointed out that these products were produced under non-hygienic conditions and have potential risk for human health. Furthermore, it was revealed that real-time PCR methods were faster and as reliable as conventional methods for cheese samples directly for the determination and identification of these microorganisms.
\end{abstract}

Keywords: Vitek 2, ISO 11290, foodborne pathogen, molecular identification, Turkey

\section{Introduction}

White cheese is the most widely produced kind of cheese in Turkey and is commonly produced in the eastern and south-eastern parts of Anatolia. Cow cheese production in 2018 reached to 622.292 tons in Turkey in official institutions reports (Turkish Statistical 
Institute, 2019). As a fermented dairy product, high protein content of white cheese creates a good habitat for microorganisms. White cheese varieties may contain different amounts of microorganisms due to the quality of the milk, production technique, packaging, transportation and storage. Particularly, the consumption of cheese made of non-pasteurized milk or dairy products, the containing microorganisms may cause an epidemic or cases with sporadic disease (Zamani-Zadeh et al., 2011).

Between these microorganisms, with the zoonotic character of pathogen Listeria spp., contaminated food is most likely to generate infection in humans. It is also an important pathogen for agriculture and food industry that can be detected in milk and dairy products, vegetables, fish, meat products and prepared foods (Ekici et al., 2004). Listeria spp. can survive in humid or dry environments, soil, plants or other living organisms for months (Carter et al., 1995). Listeria spp. may be easily contagioned orally, nosocomially or vertically WHO/FAO 2018. Food and water contaminated with the agent, mosquitos and ticks are crucial for the contagion (Farber et al., 1991). Following the contagion, people in the risk group, which may be listed as, pregnant women, newborns, old and immune deficient people are frequently affected by listeriosis (Slutsker and Schuchat, 1999). In severe infections, septicemia, meningitis and premature stillbirths are seen in humans whereas meningoencephalitis, abortus and mastitis present in domesticated animals (Farber et al., 1991).

Among Listeria species, L. monocytogenes and $L$. innocua are important bacteria that can be found in food. Both species can live under conditions such as environments with $\mathrm{pH}$ values between 4.39 and 9.4 and refrigerator conditions (Vázquez-Boland et al., 2001; Zamani-Zadeh et al., 2011). L. monocytogenes is a potent public health issue with a $30 \%$ mortality rate when contagioned (Lou and Yousef, 1999). On the other hand, L. innocua is rarely associated with a disease yet commonly found during identification. Recent studies showed that in analyses conducted using the VITEK 2 system, L innocua may be mistaken for L. monocytogenes (De Lappe et al., 2014). This finding calls attention to other methods that seem to be required for confirmation of the results.

The aim of this study is to evaluate the use of the real-time PCR (Polymerase Chain Reaction) method from cheese samples directly, faster and as reliable as compared to conventional methods to identificate L. monocytogenes and L. innocua and also to find the prevalence of Listeria spp. L. monocytogenes and L. innocua by studying the white cheese samples collected from various local town bazaars from Şanliurfa, Mardin, Gaziantep and Diyarbakır and demonstrate hygienic qualities of these products and the possible public health risks they constitute in this region.

\section{Material and methods}

In this study, 103 different fresh homemade white cheese samples collected from local town bazaars of the cities Şanlıurfa, Mardin, Gaziantep and Diyarbakır, were investigated. Samples were collected under aseptic conditions of the local bazaars as $200 \mathrm{gr}$ each. They were brought to the Department of Food Hygiene and Technologies laboratories, Harran University in cold chain, and analyses were started the very same day. The classical microbiological analyses and VITEK 2 studies were conducted by Harran University, Food Hygiene and Technologies Department Laboratory. The DNA isolations of the positive samples in Harran University, veterinary genetics laboratory and the real-time PCR analyses of the positive sample DNAs in Medical Microbiology 
Laboratories, Beykent University, Medical Faculty, in order to determine the molecular identifications.

\section{Detection of Listeria spp. with conventional methods}

The ISO (International Organization for Standardization) 11290-1/A1-2004 method was used for Listeria spp. detection following the stated protocol ISO (2004). Samples were weighed as 25 gr each with a precision balance (Cubis; Sartorius, Bohemia, NY, USA) under sterile conditions and the samples were transferred to sterile stomacher bags with an addition of $225 \mathrm{ml}$ of Enrichment Broth (M863+SR142; Oxoid Ltd, Basingstoke, UK). Samples were homogenized in a stomacher (Laboratory Blender Stomacher 400; Seward, London, UK) for 2 minutes and incubated in a $30^{\circ} \mathrm{C}$ aerobic environment for 24 hours. Afterwards, $0.1 \mathrm{~mL}$ of the homogenates were added to $10 \mathrm{ml}$ of a Fraiser Broth (CM895+SR156; Oxoid Ltd, Basingstoke, UK). Following incubation at $30^{\circ} \mathrm{C}$ for 24 hours, $0.1 \mathrm{~mL}$ of homogenate was taken from the Fraiser Broth and were cultivated into PALCAM Agar (CM 877+SR150; Oxoid Ltd, Basingstoke, UK) and Oxford Agar'a (CM 856+SR140; Oxoid Ltd, Basingstoke, UK). Mediums were incubated at $30^{\circ} \mathrm{C}$ under anaerobic conditions for 48 hours. Five colonies from any petri with a suspicion of Listeria spp. growth were transferred to Tryptic Soy Agar-Yeast Extract (TSA-YE, 0370; Difco, Toronto, $\mathrm{ON}$ ) and incubated at $30^{\circ} \mathrm{C}$ for 24 hours for purification.

\section{Detection of Listeria spp. By using VITEK 2}

The purity of the isolated suspicious colonies was controlled with Gram staining. Also, oxidase, catalase, beta hemolysis, mannitol, rhamnose, xylose, salicin, dulcite, methyl red, Voges-Proskauer, nitrate reduction and CAMP tests were applied. All colonies added at $3 \mathrm{~mL}$ sterile saline solution with sterile swabs in polystyrene test tube to made homogenous 0.5 McFarland turbidity standart suspension using with Vitek 2 DensiCHEK instrument. Then the suspension tube and VITEK 2 GP card (Biomerieux, Marcy l'Etoile, France) placed in the cassette. After that the cassette loaded on Vitek 2 Systems (Biomerieux, Marcy l'Etoile, France) following the manufacturer's guidelines.

The strains, ATCC 15313 for Listeria monocytogenes and ATCC 33090 for Listeria innocua were used as positive controls.

\section{DNA isolation}

The $25 \mathrm{gr}$ each cheese samples were transferred to sterile stomacher bags with $0.5 \mathrm{~mL}$ DNase \& RNase free water. Samples were homogenized in a stomacher (Laboratory Blender Stomacher 400; Seward, London, UK) for 2 minutes and $200 \mu \mathrm{L}$ of aqueous phase were transferred to a new $1.5 \mathrm{~mL}$ sterile micro centrifuge tube. After that, $400 \mathrm{~mL}$ of lysis buffer $(0.5 \% \mathrm{~N}$-lauryl sarcosine, $50 \mathrm{Mm}$ Tris-Cl, $25 \mathrm{mM}$ EDTA, pH 8.0) was added to the mixture, vortexed well and centrifuged $15.000 \mathrm{rpm}$ for $5 \mathrm{~min}$. The pellet was resuspended with $200 \mu \mathrm{L}$ lysis buffer and $4 \mu \mathrm{L}$ proteinase $\mathrm{K}$, vortexed well and then incubated for $1 \mathrm{~h}$ at $37^{\circ} \mathrm{C}, 300 \mu \mathrm{L}$ of NaI solution $(6 \mathrm{M} \mathrm{NaI}$ in $50 \mathrm{mM}$ Tris-Cl, $25 \mathrm{mM}$ EDTA, pH 8.0) and $500 \mu \mathrm{L}$ isopropanol were added to the suspension and then centrifuged at $15.000 \mathrm{rpm}$ for $5 \mathrm{~min}$. The pellet was washed with 35\% isopropanol, dried and then suspended in $50 \mu \mathrm{L}$ DNase \& RNase free sterile water. Isolated DNA samples were stored at $-20^{\circ} \mathrm{C}$ until the real time PCR application (Sheela and Shrinithivihahshini, 2017; Moravkova, 2017). 


\section{Identification of L. monofcytogenes and L. innocua with the real-time PCR method}

Following the nucleic acid isolations were performed from all cheese samples directly, the hly region for L. monocytogenes and lin02483 region for L. innocua were amplified two times with real-time PCR for each sample.

The real time PCR procedure was performed using the Light Cycler 480 II (Roche Diagnostics GmbH, Mannheim, Germany) system with Light Cycler 480 Probe Master (Roche Diagnostics GmbH, Mannheim, Germany) kit. The primers and probes used for the hly and lin02483 regions according to the manufacturer's guide are shown in Table 1 (Rodríguez-Lázaro et al., 2004; Benito et al., 2017). To performed quantification, plasmid standarts with known concentrations were purchased from Bioeksen Ltd, Istanbul.

Table 1. The primer and probe sets used in real time PCR analyses for L. monocytogenes and L. innocua identification

\begin{tabular}{c|c|c}
\hline L. monocytogenes (hly) & & Ref. \\
\hline hlyQFa (Forward primer) & 5-CAT GGC ACC ACC AGC ATC T-3 & \\
hlyQRa (Reverse primer) & 5-ATC CGC GTG TTT CTT TTC GA-3 & \\
hlyQP (TaqMan probe) & 5-FAM-CGC CTG CAA GTC CTA AGA CGC \\
\hline L. innocua (lin02483) & CA-TAMRA-3 & Rodríguez-Lázaro et al., \\
\hline lipHQFa (Forward primer) & 5-AAC CGG GCC GCT TAT GA-3 & \\
lipHQRa (Reverse primer) & 5-CGA ACG CAA TTG GTC ACG-3 & \\
lipHQP (TaqMan probe) & 5-FAM-TTC GAA TTG CTA GCG GCA CAC \\
\hline
\end{tabular}

$5 \mu 1$ of isolated DNA ( $50 \mathrm{ng} / \mu \mathrm{l})$ were added to each real time PCR reactions, making the final volume $20 \mu \mathrm{l}$. The real time PCR protocol used was; following the $10 \mathrm{~min}$ denaturation in $95^{\circ} \mathrm{C}, 45$ cycles of $10 \mathrm{sec}$ in $95^{\circ} \mathrm{C}, 60 \mathrm{sec}$ in $62^{\circ} \mathrm{C}$ for a single read. The positive controls ATCC 15313 for L. monocytogenes and ATCC 33090 for L. innocua were included to all Real-time PCR experiments.

\section{Sanger sequencing of hly and iapgene}

To the confirmation of real-time PCR results, L. monocytogenes and L. innocua positive 7 samples were done Sanger sequencing using the specific primers for hly and iap genes based on Rodríguez-Lázaro et al. study in 2004, Sanger sequence were performed with the ABI 3130XL sequencing instrument (Table 2). The sequencer fasta files were aligned using the BLAST program against the known ones in the GenBank database of the National Centre for Biotechnology Information (NCBI, http://www.ncbi.nlm.nih.gov/).

Table 2. Distribution of the Listeria monocytogenes identification results for VITEK 2 GP card and "hly" Real Time PCR analysis

\begin{tabular}{c|c|c}
\hline Listeria monocytogenes & $\begin{array}{c}\text { VITEK 2 GP card } \\
\text { (n) }\end{array}$ & $\begin{array}{c}\text { Hly Real Time PCR analysis } \\
(\mathbf{n})\end{array}$ \\
\hline Positive & 6 & 6 \\
Negative & 97 & 97 \\
\hline
\end{tabular}




\section{Results}

From 103 fresh cheese samples, 7 (6,8\%) samples were found Listeria spp. positive using the conventional culturing method (Table 3). All Listeria spp. isolates gave Gram positive, oxidase negative and catalase positive reactions. Figure 1 shows the Listeria spp. positive colonies on Oxford agar.

Table 3. Distribution of Listeria spp. positive samples

\begin{tabular}{c|c|c}
\hline City & $\begin{array}{c}\text { Number of samples collected } \\
(\mathbf{n})\end{array}$ & $\begin{array}{c}\text { Listeria spp. Positive } \\
(\boldsymbol{\%})\end{array}$ \\
\hline Şanlıurfa & 27 & $3(2.91 \%)$ \\
Mardin & 26 & $1(0.97 \%)$ \\
Gaziantep & 25 & $2(1.94 \%)$ \\
Diyarbakır & 25 & $1(0.97 \%)$ \\
Total & 103 & $7(6.80 \%)$ \\
\hline
\end{tabular}

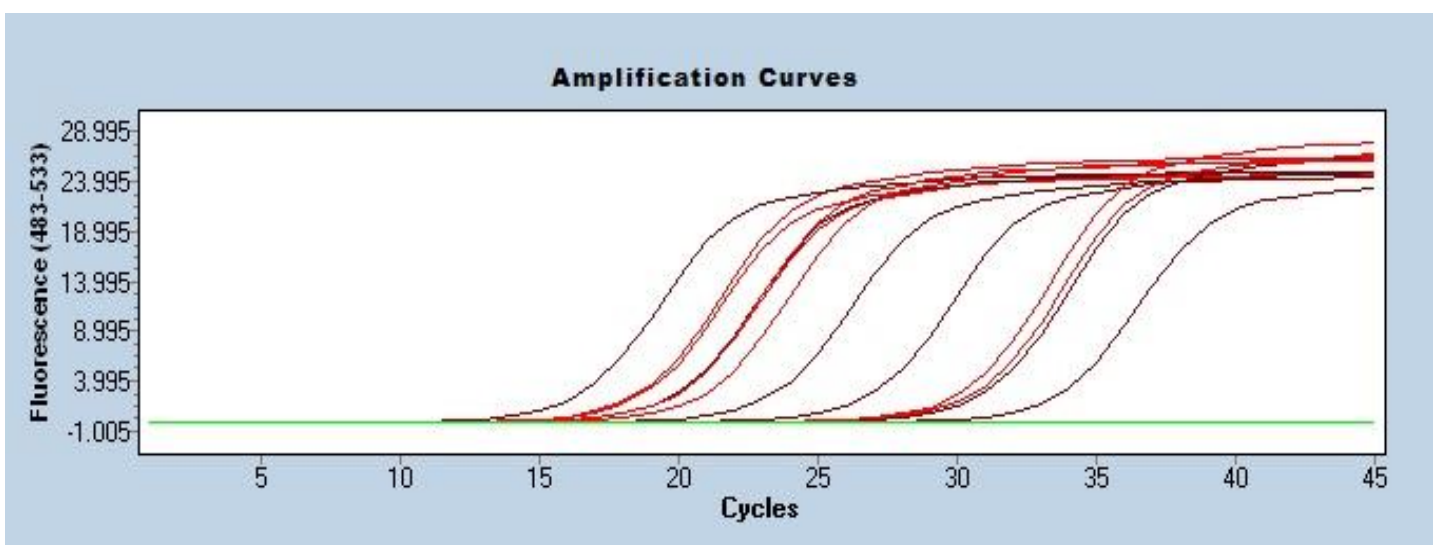

Figure 1. Amplification curves of Real-time PCR experiments for positive samples, negative samples and standards (Red: positive samples, Brown: Standarts, Green: Negative Samples)

Listeria spp. positive colonies were identified as L. monocytogenes or L. innocua with a $99 \%$ possibility by the VITEK 2 system GP card. The analysis on VITEK 2 system took 8.25 hours.

After DNA extraction from cheese samples directly, real-time PCR was perfomedby the amplification of the hly and lin02483 regions to the detect L. monocytogenes or L. innocua, respectively. Results are shown in Table 2 and Table 4 for L. monocytogenes and L. innocua, respectively. The real time PCR procedure after isolation took an hour and 20 minutes on the Light Cycler 480 II system. Amplification curves of real-time PCR experiments for positive samples, negative samples and standarts are shown in Figure 1 for L. monocytogenes and L. innocua, respectively. The results of VITEK 2 and real-time PCR were found the same at this study. All real-time PCR results were also confirmed by Sanger sequencing alignment results. Table 5 showed that the quantification results of positive cheese samples. Although the existence of all positive samples is not suitable for human consumption, the quantitative amounts were examined considering that the situation that will make a difference may be due to quantitation with VITEK 2 System but no difference was found. 
Table 4. Distribution of the Listeria innocua identification results for VITEK 2 GP card and “lin02483” Real Time PCR analysis

\begin{tabular}{c|c|c}
\hline Listeria innocua & VITEK 2 GP card & Lin02483 Real Time PCR analysis \\
(n)
\end{tabular}

Table 5. Quantification results of positive cheese samples via Real-time PCR

\begin{tabular}{c|c|c|c|c}
\hline Name & $\mathbf{C p}$ & $\begin{array}{c}\text { Calculated } \\
\text { Concentration }\end{array}$ & $\begin{array}{c}\text { Known } \\
\text { Concentration }\end{array}$ & Strain \\
\hline $\mathbf{1}$ & 17.14 & $5.14 \mathrm{E}+04$ & & L. monocytogenes \\
$\mathbf{2}$ & 18.28 & $2.46 \mathrm{E}+04$ & & L. innocua \\
$\mathbf{3}$ & 18.26 & $2.50 \mathrm{E}+04$ & & L. monocytogenes \\
$\mathbf{4}$ & 19.66 & $1.01 \mathrm{E}+04$ & & L. monocytogenes \\
$\mathbf{5}$ & 19.66 & $1.01 \mathrm{E}+04$ & & L. monocytogenes \\
$\mathbf{6}$ & 19.7 & $9.85 \mathrm{E}+03$ & & L. monocytogenes \\
$\mathbf{7}$ & 20.7 & $5.19 \mathrm{E}+03$ & 100000 & \\
Standard 1 & 16.06 & $1.03 \mathrm{E}+05$ & 10000 & \\
Standard 2 & 19.6 & $1.05 \mathrm{E}+04$ & 1000 & \\
Standard 3 & 23 & $1.17 \mathrm{E}+03$ & 100 & \\
Standard 4 & 26.61 & $1.14 \mathrm{E}+02$ & 10 & \\
Standard 5 & 30.69 & $8.23 \mathrm{E}+00$ & 1 & \\
Standard 6 & 33.25 & $1.41 \mathrm{E}+00$ & & \\
\hline
\end{tabular}

\section{Discussion}

Although cow milk is commonly used for white cheese production, sheep and goat milk also has its place in production in the region. The production of white cheese sold in the local bazaars is generally done by traditional ways in family businesses, but hygienic conditions are not fully provided. Especially, the white cheese produced in Şanlıurfa, following the milking, milk is yeasted in milking temperature and strained with a thin cloth called 'parzın' to give its final shape. White cheeses are presented for consumption without any salt and no pasteurization is applied before production. Lack of pasteurization increases the risk of zoonotic foodborne pathogen contamination in dairy products. For this reason, in this study, the entity of Listeria spp., an important pathogen of fresh white cheese, was investigated in fresh white cheese samples collected from local town bazaars of the region. The Turkish Food Codex regulations on Microbiological Criteria states that the existence of L. monocytogenes in a $25 \mathrm{gr}$ cheese sample is not suitable for consumption (Turkish Food Codex, 2011). According to the regulations, 7 of 103 cheese samples studied are found to be not suitable for consumption.

As a result of this study, 7 (6.8\%) of the fresh cheese samples were found to be Listeria spp. positive with 6 of the isolates were identified as L. monocytogenes and one as L. innocua using real-time PCR and VITEK 2 system.

When the national studies conducted on Listeria spp. (L. monocytogenes and L. innocua) existence in our country were investigated, no real time PCR based method is used but by the use of conventional methods statistical studies are conducted in various cities of Turkey (Table 6) (Kara et al., 1999; Vural et al., 2010). 
Table 6. Listeria spp., L. monocytogenes and L. innocua ratios in cheese determined using the classical methods

\begin{tabular}{c|c|c|c|c|c}
\hline Researcher & City & N & Listeria spp. & L. monocytogenes & L. innocua \\
\hline Kara et al. (1999) & Erzurum & 50 & $4(8 \%)$ & & \\
Sağun et al. (2001) & Van & 254 & $13(5.11 \%)$ & $10(3.93 \%)$ & $1(0.39 \%)$ \\
Gülmez and Güven (2001) & Kars & 80 & $6(7.5 \%)$ & & \\
Uysal and Ang (2003) & Istanbul & 275 & & $11(4 \%)$ & \\
Aygün and Pehlivanlar (2005) & Antakya & 85 & $7(8,23 \%)$ & $2(2,35 \%)$ & $3(3,52 \%)$ \\
Akkaya and Alişarlı (2006) & Afyon & 100 & & $6(6 \%)$ & \\
Arslan and Özdemir (2007) & Bolu & 142 & $47(33.1 \%)$ & $13(9.2 \%)$ & $13(9.2 \%)$ \\
Azak (2012) & Erzincan & 100 & $3(3 \%)$ & $3(3 \%)$ & \\
\hline
\end{tabular}

Although national studies were not conducted using real time PCR, the ratios found are similar to other findings, with exclusion of Arslan and Özdemir (2007). Thus, it can be said that our findings are compatible with other studies conducted.

Otherwise; Dümen et al. (2011) were investigated 700 milk and dairy product samples by classical and molecular microbiological methods. 20 samples of 700 were positive as L. monocytogenesis. PCR results were same with classical microbiological methods. The positivity rates obtained in our study were found to be higher than Dümen's study ratio (Dümen et al., 2011).

Once international publications are taken into account, molecular and real time PCR based studies appear on identification of Listeria spp, L. monocytogenes and L. innocua (El-Marrakchi et al., 1993; Rossmanith et al., 2010). El-Marrakchi et al. (1993) conducted a study in Algeria and they reported L. monocytogenes in 1 (4.54\%) of 22 fresh cheese samples. In addition, Silva et al. (2003) study, where they searched for L. monocytogenes in the critical checkpoints in Brazil for minas cheese production. They investigated 218 samples comprising 54 food, 107 equipment, 22 worker and 35 environmental samples and reported 13 Listeria spp. positive cases. Nine of the samples were identified as L. innocua, 2 L. grayi and 2 L. monocytogenes by Silva et al. (2003). Also, in a study where Hein et al. (2001) used the real-time PCR method for identifying Listeria spp. in milk, they looked for 42 L. monocytogenes and 33 L. innocua strains and showed that real-time PCR method is safe and highly reliable.

On the other hand, De Lappe et al. (2014) did a VITEK 2 system based study and reported that this method is highly reliable yet may not identify L. monocytogenes and L. innocua correctly. In our study we compared the VITEK 2 system and real-time PCR method and found no differences in their ability to identify L. monocytogenes and L. innocua. In contrary, De Lappe et al. (2014) study underlined the need of a faster and more reliable method for detection of L. monocytogenes that an important foodborne pathogen for human health. Regarding international publications, real time PCR method is stated as a faster and as reliable as others for Listeria spp. L. monocytogenes and L. innocua identification when compared to the conventional ISO methods (Rossmanith et al., 2010; Gianfranceschi et al., 2014).

Sallen et al. (1996) 23S rRNA and 16S rRNA regions using the primer and amplicons used for all of the Listeria species were analysed. However, 23S rRNA was recommended for L. innocua and L. monocytogenes, and $16 \mathrm{~S}$ rRNA was not distinctive. Czajka et al. (1993) 16S rRNA genes (16S rDNA) of L. innocua and L. monocytogenes species were detected by using sequence analysis. Chen et al. (2017) in the cheese-borne listeriosis 
outbreak, Schmitz-Esser et al. (2015), Lassen et al. in 2016, Salazar et al. (2018), in the outbreaks of soft cheese, L. monocytogenes serotypes and similar strains to determine the SNP 's made by sequence analysis. For L. innocua, Facinelli et al. (1993) identified strains of tetracycline in 12 strains in mozarella by DNA sequencing. Buchrieser et al. (2003) compared the genes related to the development and pathogenicity of these two Listeria species, which are food pathogens, with Staphylococcus and Bacillus sequence analysis. In our study, 6 L. monocytogenes and 1 L. innocua specimens which we found positive were detected by sequence analysis and confirmed.

\section{Conclusions}

Finally, our findings showed that the cheese produced in Turkey and presented for consumption is not Listeria spp. and L. monocytogenes free. The raw milk used in white cheese production without any pasteurization or heat treatment and non-hygienic production and storage conditions may be the cause of the lack of hygiene in these products. Moreover, our findings showed that the real-time PCR method is faster and as reliable as others compared to the conventional methods and can be easily applied in laboratories with experience in molecular techniques. Comprehensive studies should be conducted to identify different Listeria spp. by collecting much more cheese and milk samples to protect public health.

\section{REFERENCES}

[1] Akkaya, L., Alişarlı, M. (2006): An Investigation on the Presence of Listeria monocytogenes and Salmonella spp. in Retail Cheeses Consumed in Afyonkarahisar Province, Turkey. - Van Vet. J. 17: 87-91.

[2] Arslan, S., Özdemir, F. (2007): Prevalence and antimicrobial resistance of Listeria spp. in homemade white cheese. - Food Control 19: 360-363.

[3] Aygün, O., Pehlivanlar, S. (2005): Listeria spp. in the raw milk and dairy products in Antakya Turkey. - Food Control 17: 676-679.

[4] Azak, M. G., Kılıç, H., Hızlısoy, H., Abay, S. (2012): Isolation and Identification of Listeria spp. from Tulum Cheese of Erzincan City. - J. Fac. Vet. Med. Univ. Erciyes 9: 149-156.

[5] Benito, S., López, A., Lizana, X., Lope, S., Carbó, R., Del Valle, L. J., Piqué, N. (2017): Presence of Listeria monocytogenes in Prepared Foods: Analysis of Influencing Factors. Journal of Food Processing and Preservation 41(2): e12842.

[6] Buchrieser, C., Rusniok, C., Kunst, F., Cossart, P., Glaser, P., Listeria Consortium (2003): Comparison of the genome sequences of Listeria monocytogenes and Listeria innocua: clues for evolution and pathogenicity. - FEMS Immunol. Med. Microbiol. 35(3): 207-213.

[7] Carter, G., Chengappa, M. M., Roberts, A. W. (1995): Essentials of Veterinary Microbiology. - USA, Willams and Wilkins.

[8] Chen, Y., Luo, Y., Carleton, H., Timme, R., Melka, D., Muruvanda, T., Fritzinger, A. (2017): Whole genome and core genome multilocus sequence typing and single nucleotide polymorphism analyses of Listeria monocytogenes isolates associated with an outbreak linked to cheese, United States 2013. - Appl. Environ. Microbiol. 83: e00633-17.

[9] Czajka, J., Bsat, N., Piani, M., Russ, W., Sultana, K., Wiedmann, M., Batt, C. A. (1993): Differentiation of Listeria monocytogenes and Listeria innocua by $16 \mathrm{~S}$ rRNA genes and intraspecies discrimination of Listeria monocytogenes strains by random amplified polymorphic DNA polymorphisms. - Appl. Environ. Microbiol. 59: 304-308. 
[10] De Lappe, N., Lee, C., O’Connor, J., Cormican, M. (2014): Misidentification of Listeria monocytogenes by the VITEK 2 System. - J Clin Microbiology 52: 3494-5.

[11] Dümen, E., Issa, G., İkiz, S., Bağcigil, F., Özgür, Y., Kahraman, T., Ergin, S., Yeşil, O. (2011): Determining Existance and Antibiotic Susceptibility Status of Listeria monocytogenes Isolated from Dairy Products, Serological and Moleculer Typing of the Isolates. - Kafkas Univ. Vet. Fak. Derg. 17: 111-119.

[12] Ekici, K., İşleyici, Ö., Sağun, E. (2004): The Existence of Listeria monocytogenes in Milk and Milk Products. - Van Vet. J. 15: 97-101.

[13] El-Marrakchi, A., Hamama, A., Othmani, F. (1993): Occurrence of L. monocytogenes in milk and dairy products produced or imported into Morocco. - J. Food Prot. 56: 256-259.

[14] Facinelli, B., Roberts, M. C., Giovanetti, E., Casolari, C., Fabio, U., Varaldo, P. E. (1993): Geneticbasis of tetracyclineresistance in food-borne isolates of Listeria innocua. - Appl. Environ. Microbiol. 59: 614-616.

[15] Farber, J. M., Daley, E., Coates, F. (1991): Feeding trials of Listeria monocytogenes with a nonhuman primate model. - J. Clin. Microbiol. 29: 2606-2608.

[16] Gianfranceschi, M. V., Rodriguez-Lazaro, D., Hernandez, M., González-García, P., Comin, D., Gattuso, A., Delibato, E., Sonnessa, M., Pasquali, F., Prencipe, V., SreterLancz, Z., Saiz-Abajo, M. J., Pèrez-De-Juan, J., Butrón, J., Kozačinski, L., Tomic, D. H., Zdolec, N., Johannessen, G. S., Jakočiūnè, D., Olsen, J. E., De Santis, P., Lovari, S., Bertasi, B., Pavoni, E., Paiusco, A., De Cesare, A., Manfreda, G., De Medici, D. (2014): European validation of a real-time PCR-based method for detection of Listeria monocytogenes in soft cheese. - Int. J. Food Microbiol. 184: 128-133.

[17] Gülmez, M., Güven, A. (2001): Investigation of Campylobacter, Salmonella and Listeria spp. from Turkish white and Çeçil Cheese. - Kafkas Üniv. Vet. Fak. Derg. 7: 155-161.

[18] Hein, I., Klein, D., Lehner, A., Bubert, A., Brandl, E., Wagner, M. (2001): Detection and quantification of the iap gene of Listeria monocytogenes and Listeria innocua by a new real-time quantitative PCR assay. - Res. Microbiol. 152: 37-46.

[19] ISO (International Organization for Standardization) (2004): Microbiology of Food and animal Feeding Stuffs e Horizontal Method for the Detection and Enumeration of Listeria monocytogenes e Part 1: Detection Method. Amendment 1: Modification of the Isolation media and the Haemolysis Test, and Inclusion of Precision Data. - ISO 11290-1: 1996/Amd 1. Geneva, Switzerland.

[20] Kara, A., Algur, Ö. F., Kaya, M. (1999): Investigation on the Isolation and Identification of the Listeria Species in the White and Civil Cheeses Purchased From Erzurum Region. Tr. J. of Biol. 23: 331-337.

[21] Lassen, S. G., Ethelberg, S., Björkman, J. T., Jensen, T., Sørensen, G., Jensen, A. K., Mølbak, K. (2016): Two Listeria outbreaks caused by smoked fish consumption-using whole-genome sequencing for outbreak investigations. - Clin. Microbiol. Infect. 22: 620624.

[22] Lou, Y., Yousef, A. E. (1999): Characteristics of Listeria monocytogenes important to food processors. - Foodborne Pathogens: 131-224.

[23] Moravkova, M., Verbikova, V., Michna, V., Babak, V., Cahlikova, H., Karpiskova, R., Kralik, P. (2017): Detection and Quantification of Listeria monocytogenes in Ready-to-eat Vegetables, Frozen Vegetables and Sprouts Examined by Culture Methods and Real-time PCR. - Journal of Food and Nutrition Research 5: 832-837.

[24] Rodríguez-Lázaro, D., Hernández, M., Scortti, M., Esteve, T., Vázquez-Boland, J. A., Pla, M. (2004): Quantitative Detection of Listeria monocytogenes and Listeria innocuaby RealTime PCR: Assessment of hly, iapand lin02483 Targets and AmpliFluor Technology. Appl. Environ. Microbiol. 70: 1366-1377.

[25] Rossmanith, P., Mester, P., Wagner, M., Schoder, D. (2010): Demonstration of the effective performance of a combined enrichment/real-time PCR method targeting the prfA gene of Listeria monocytogenes by testing fresh naturally contaminated acid curd cheese. - Lett. Appl. Microbiol. 51: 480-484. 
[26] Sağun, E., Sancak, Y. C., İşleyici, Ö., Ekici, K. (2001): The Presence and Prevalence of Listeria Species in Milk and Herby Cheese in and Around. - Van Turk. J. Vet. Anim. Sci. 25: $15-19$.

[27] Salazar, J. K., Gonsalves, L. J., Schill, K. M., Leon, M. S., Anderson, N., Keller, S. E. (2018): Complete Genome Sequence of Listeria monocytogenes DFPST0073, Isolated from Imported Mexican Soft Cheese. - Genome Announc. 6: e00496-18.

[28] Sallen, B., Rajoharison, A., Desvarenne, S., Quinn, F., Mabilat, C. (1996): Comparative analysis of $16 \mathrm{~S}$ and 23S rRNA sequences of Listeria species. - Int. J. Syst. Evol. Microbiol. 46: 669-674.

[29] Schmitz-Esser, S., Müller, A., Stessl, B., Wagner, M. (2015): Genomes of sequence type 121 Listeria monocytogenes strains harbor highly conserved plasmids and prophages. Frontiers in Microbiol. 6: 380.

[30] Sheela, M. M., Shrinithivihahshini, N. D. (2017): Pervasiveness of Listeria monocytogenes in milk and dairy products. - J Food Microbiol Saf Hyg 2: 2476-2059.

[31] Silva, I. M. M., Almeida, R. C. C., Alves, M. A. O., Almeida, P. F. (2003): Occurrence of Listeria spp. in critical control points and the environment of minas frescal cheese processing. - Int. J. Food Microbiol. 81(3): 241-248.

[32] Slutsker, L., Schuchat, A. (1999): Listeriosis in humans. - In: Ryser, E. T., Marth, E. H. (eds.) Listeria, Listeriosis, and Food Safety. Marcel Dekker, Inc., pp.75-95.

[33] Turkish Food Codex. (2011): Regulation on Microbiological Criteria. - Authorization Law: 5996. Official Gazette: 28157.

[34] Turkish Statistical Institute. (TUIK) (2019): Production of Milk and Dairy Products. http://www.tuik.gov.tr/PreHaberBultenleri.do?id=18717.

[35] Uysal, H. K., Ang, Ö. (2003): Listeria Species Isolated from Milk and Dairy Products. Turk Mikrobiol. Cem. Derg. 33: 163-169.

[36] Vázquez-Boland, J. A., Kuhn, M., Berche, P., Chakraborty, T., Dominguez-Bernal, G., Goebel, W., González-Zorn, B., Wehland, J., Kreft, J. (2001): Listeria Pathogenesis and Molecular Virulence Determinants. - Clin. Microbiol. Rev. 14: 584-640.

[37] Vural, A., Erkan, M., Güran, H. Ş. (2010): The Examination of the Microbiologic Quality in Örgü Cheese (Braided Cheese) Samples. - Kafkas Univ. Vet. Fak. Derg. 4: 53-58.

[38] WHO/FAO (2018): Risk assessment of Listeria monocytogenes in ready-to-eat foods, Interpretative Summary. - Microbiological risk assesment series 4: 1-78. http://seafood.oregonstate.edu/.

[39] Zamani-Zadeh, M., Sheikh-Zeinoddin, M., Soleimanian-Zad, S. (2011): Prevalence and Characterization of Listeria Species in Domestic and Industrial Cheeses of Isfahan Region. - Iran J. Public Health 40: 98-104. 